\title{
Enhancement of Mechanical and Dynamic Mechanical Properties of Hydrophilic Nanoclay Reinforced Polylactic Acid/Polycaprolactone/Oil Palm Mesocarp Fiber Hybrid Composites
}

\author{
Chern Chiet Eng, ${ }^{1}$ Nor Azowa Ibrahim, ${ }^{1}$ Norhazlin Zainuddin, ${ }^{1}$ Hidayah Ariffin, ${ }^{2}$ \\ Wan Md. Zin Wan Yunus, ${ }^{3}$ and Yoon Yee Then ${ }^{1}$ \\ ${ }^{1}$ Department of Chemistry, Faculty of Science, University Putra Malaysia, 43400 UPM Serdang, Selangor, Malaysia \\ ${ }^{2}$ Department of Bioprocess Technology, Faculty of Biotechnology and Biomolecular Sciences, University Putra Malaysia, \\ 43400 UPM Serdang, Selangor, Malaysia \\ ${ }^{3}$ Chemistry Department, Centre for Defence Foundation Studies, National Defence University of Malaysia, Kem Sungai Besi, \\ 57000 Kuala Lumpur, Malaysia
}

Correspondence should be addressed to Nor Azowa Ibrahim; norazowa@science.upm.edu.my

Received 1 March 2014; Accepted 7 April 2014; Published 27 April 2014

Academic Editor: Jan-Chan Huang

Copyright (C) 2014 Chern Chiet Eng et al. This is an open access article distributed under the Creative Commons Attribution License, which permits unrestricted use, distribution, and reproduction in any medium, provided the original work is properly cited.

In previous studies, the effect of the addition of $1 \mathrm{wt} \%$ hydrophilic nanoclay on polylactic acid (PLA)/polycaprolactone (PCL)/oil palm mesocarp fiber (OPMF) biocomposites was investigated by tensile properties, thermogravimetric analysis (TGA), and scanning electron microscopy (SEM). The current studies focus on the effect of addition of 1 wt $\%$ hydrophilic nanoclay on mechanical (flexural and impact properties) and dynamic mechanical properties of composites. The composites were characterized by the Fourier transform infrared spectroscopy (FTIR) and dynamic mechanical analysis (DMA). FTIR spectra show that peak shifting occurs when $1 \mathrm{wt} \%$ hydrophilic nanoclay was added to composites. The addition of $1 \mathrm{wt} \%$ hydrophilic nanoclay successfully improves the flexural properties and impact resistance of the biocomposites. The storage modulus of biocomposites was decreased when nanoclay was added which indicates that the stiffness of biocomposites was reduced. The loss modulus curve shows that the addition of nanoclay shift two $t_{g}$ in composites become closer to each other which indicates that the incorporation of nanoclay slightly compatibilizes the biocomposites. Tan $\delta$ indicated that hybrid composites dissipate less energy compared to biocomposites indicate that addition of clay to biocomposites improves fiber/matrix adhesion. Water sorption test shows that the addition of nanoclay enhances water resistance of composites.

\section{Introduction}

In our preliminary studies [1], we reported that the incorporation $1 \mathrm{wt} \%$ of hydrophilic nanoclay in polylactic Acid (PLA)/polycaprolactone (PCL) blends successfully enhance the morphology, mechanical and thermal properties of the blends. Therefore, we choose incorporation of $1 \mathrm{wt} \%$ of hydrophilic nanoclay into PLA/PCL/oil palm mesocarp fiber (OPMF) biocomposites to study the effect of nanoclay on biocomposites.
In our previous paper [2], we reported that the addition of $1 \mathrm{wt} \%$ hydrophilic nanoclay to PLA/PCL/OPMF biocomposites increases the tensile strength and elongation at break of biocomposites around $8.48 \%$ and $32.14 \%$, respectively, at $10 \%$ fiber loading. Besides, thermogravimetric analysis (TGA) results show that the presence of clay increases the thermal stability of the biocomposites. Scanning electron microscopy (SEM) micrographs revealed that PLA/PCL/OPMF biocomposites consist of cavity which indicated poor fiber/matrix adhesion while micrographs of PLA/PCL/OPMF/clay hybrid 
composites show better fiber/matrix adhesion as no cavity is present at facture surfaces.

Natural fiber as reinforcement filler in polymer composites has received increasing attention from researchers as natural fibers have many significant advantages over synthetic fibers. They are environmentally friendly, fully biodegradable, abundantly available, renewable, and cheap and have low density [3]. However, there are some disadvantages such as poor wetability, incompatibility with some polymeric matrices, and high moisture adsorption which restrict their usage in polymer composites [4].

The oil palm (Elaeis guineensis) originates from South Africa which grows well in all tropical areas of the world and it has become one of the main industrial crops. Malaysian palm oil industry has grown tremendously over the last 25 years and has become the world's leading producer and exporter of palm oil [5]. For every kg of palm oil produced, approximately $4 \mathrm{~kg}$ of dry biomass is produced, excluding palm oil mill effluent (POME). In 2010, the amount of mesocarp fiber available was $10.80 \mathrm{Mt}$ /year [6]. Therefore, there is huge amount of fiber that can be utilized instead of being discarded as waste. Traditionally, the mesocarp fiber is mixed with kernel shell and is being utilized as solid fuel to generate electricity for the mill.

Polylactic acid (PLA) is biodegradable polymer with good mechanical properties, thermal plasticity, and biocompatibility. However, PLA is a comparatively brittle and stiff polymer with low deformation at break. Therefore, modification of PLA is needed in order to compete with other flexible polymers such as polypropylene or polyethylene [7]. Polycaprolactone (PCL) is flexible semicrystalline biodegradable polymer with low melting point and exceptional blend compatibility. High flexibility of PCL can be considered as a good plasticizer for PLA compared to low molecular weight plasticizers as it does not migrate to the surface of the blended samples and the physical properties cannot be debased [8].

Recently, many studies have been conducted by academic or industrial researcher on biodegradable polymer in order to replace conventional nonbiodegradable polymer which causes major drawback to the environment. However, the cost of biodegradable polymer is comparatively higher than petrochemical based nonbiodegradable polymer which limits its application. The incorporation of cheap natural fibers as reinforcement filler into biodegradable polymer is an alternative to reduce its cost.

Hybrid composites are materials made by combining two or more different types of fillers in a single matrix. Although several fillers can be incorporated into the hybrid system, a combination of only two types of fillers would be more beneficial. By careful selection of the reinforcing fillers/fibers, the performance properties of the resulting composite can be significantly improved while the material cost can be substantially reduced [9]. The properties of hybrid composites depend on the individual components in which there is a more favourable balance between the inherent advantages and disadvantages. Besides, the advantages of one type of filler could complement the other filler in hybrid composite that contains two or more types of fillers. Through proper material design, a hybrid composite with balance in cost and performance could be obtained [10].

Kord [11] investigates the effect of nanoclay on polypropylene (PP)/hemp fiber composites. The increment of nanoclay loading is up to $3 \%$ increase in tensile modulus, tensile strength, and elongation at break of composites. However, the increment of nanoclay loading decreases the impact strength. Besides, the increment of nanoclay loading significantly decreases water absorption and swelling thickness of composites. The dynamic mechanical behaviour and fire properties of composites were improved by the addition of nanoclay. X-ray diffraction (XRD) shows that the dispersion of nanoclay in the hemp fiber/PP samples is not exfoliated.

The aim of incorporation of cheap natural fiber (OPMF) into expensive biodegradable polymer (PLA and PCL) was to reduce its cost. The addition of hydrophilic fiber to hydrophobic matrix will reduce the mechanical strength as incompatibility between fiber and matrix; therefore the objective of this paper is to investigate the effect of addition of $1 \mathrm{wt} \%$ of hydrophilic nanoclay on mechanical, dynamic mechanical, morphology, and water absorption properties of PLA/PCL/OPMF/nanoclay hybrid composites by melt intercalation. Various characterization techniques such as the Fourier transform infrared spectroscopy (FTIR) and dynamic mechanical analysis (DMA) were used to study the effect of addition of nanoclay on the properties of PLA/PCL/OPMF/nanoclay hybrid composites.

\section{Experimental}

2.1. Materials. All reactions were carried out by using reagent grade chemicals (>98\% purity) without further purification. The hydrophilic nanoclay (Nanomer PGV) was purchased from Sigma-Aldrich and used as received. Polylactide Resin 4060D was supplied by NatureWorks while polycaprolactone (CAPA 650) was supplied by the Solvay caprolactone. Oil palm mesocarp fibers were obtained from Felda Palm Ind. Sdn Bhd., Serting Hilir.

2.2. Preparation of Hybrid Composites. The composites were prepared by melt blending technique where the composition of PLA and PCL was kept constant at $85 \mathrm{wt} \%$ and $15 \mathrm{wt} \%$, respectively, in blend, while the clay content was constant at $1 \mathrm{wt} \%$. Only the content of OPMF varies from $0 \%$ to $30 \%$. PLA, PCL, nanoclay, and OPMF were manually premixed in a container and fed into Brabender Plastograph EC at $170^{\circ} \mathrm{C}$ with rotor speed of $50 \mathrm{rpm}$ for 10 minutes. The products were then compression moulded into sheets of $1 \mathrm{~mm}$ thickness by an electrically heated hydraulic press with a force of $1500 \mathrm{kN}$ at $160^{\circ} \mathrm{C}$ for 10 minutes. The sample sheets were then used for further characterization.

\subsection{The Fourier Transform Infrared Spectroscopy (FTIR).} Perkin Elmer Spectrum 100 series spectrometer equipped with attenuated total reflectance (ATR) was used to determine the functional groups and types of the bonding of the samples with the infrared spectra recorded in the range of 
frequency of 280 to $4000 \mathrm{~cm}^{-1}$ with the resolution of $4 \mathrm{~cm}^{-1}$ and number of scan being 16 scans.

2.4. Tensile Properties. Tensile properties measurement was performed by Instron machine model 4301, with grip attachment distance of $45 \mathrm{~mm}$. Load of $1.0 \mathrm{kN}$ was applied at constant crosshead speed of $5 \mathrm{~mm} \mathrm{~min}^{-1}$. Computerized Instron (Software series 9, national instruments GPIB PC2/2a, and NI-488.2) was used to process data. Test specimens were prepared and stamped in compliance with ASTM D638 dumbbell parameters. Sample thickness was measured with Mitutoyo Digimatic Indicator, type IDF-112, having measuring accuracy of $\pm 0.001 \mathrm{~mm}$.

2.5. Flexural Properties. The flexural strength and modulus were measured with Instron Universal Testing Machine 4301 according to ASTM D790. The size of the samples testing is $127 \mathrm{~mm} \times 12.7 \mathrm{~mm} \times 3 \mathrm{~mm}$. The crosshead speed is $1.3 \mathrm{~mm} / \mathrm{min}$ and the support span length is $48 \mathrm{~mm}$. Data was processed with computerized Instron (Software series 9, national instruments GPIB PC2/2a, and NI-488.2).

2.6. The Izod Impact Strength. The Izod impact test was carried out according to ASTM D256 standard using an impact tester (The IZOD Impact Tester). The sample size is $63.5 \times 12.7 \times 3 \mathrm{~mm}$, while the notch length is $2.54 \mathrm{~mm}$. The energy required to break the samples was divided by unit area of residual cross section of sample to obtain impact resistance value. The impact strength $(\mathrm{J} / \mathrm{m})$ was calculated by dividing the energy obtained $(\mathrm{J})$ with the thickness of specimen (m).

2.7. Thermogravimetric Analysis (TGA). TGA testing was conducted in accordance with ASTM E1131. Perkin Elmer TGA7 was used for thermogravimetric analysis of samples where about $15 \mathrm{mg}$ of the samples was heated from $35^{\circ} \mathrm{C}$ to $800^{\circ} \mathrm{C}$ with the heating rate of $10^{\circ} \mathrm{C} / \mathrm{min}$. Nitrogen gas was pumped with the flow rate of $20 \mathrm{~mL} / \mathrm{min}$ in order to let the analysis be carried out in nitrogen atmosphere.

2.8. Dynamic Mechanical Analysis (DMA). DMA testing was conducted in accordance with ASTM D5023-07. The Perkin Elmer Model Pyris Diamond DMA was used. Samples were tested under the condition of static force $10 \mathrm{~N}$ and dynamic force $8 \mathrm{~N}$ with $1 \mathrm{~Hz}$ frequencies. Scan was done from $-100^{\circ} \mathrm{C}$ to $130^{\circ} \mathrm{C}$ at $2^{\circ} \mathrm{C} / \mathrm{min}$ rate with sample dimensions being $1 \mathrm{~mm}$ in thickness and $30 \mathrm{~mm}$ in length by using bending mode.

2.9. Scanning Electron Microscopy (SEM). The surface morphology of fracture surface was observed with SEM JEOL JSM-6400. The fracture surface was obtained from plain strain fracture tensile tested specimens and was sputter coated with gold using biorad coating system before viewing.

2.10. Water Sorption Test. Water absorption studies were performed following the ASTM D638, type M3 standard. The films were cut into dumbbell shapes and dried at room temperature overnight to reach the constant weight. Then, the

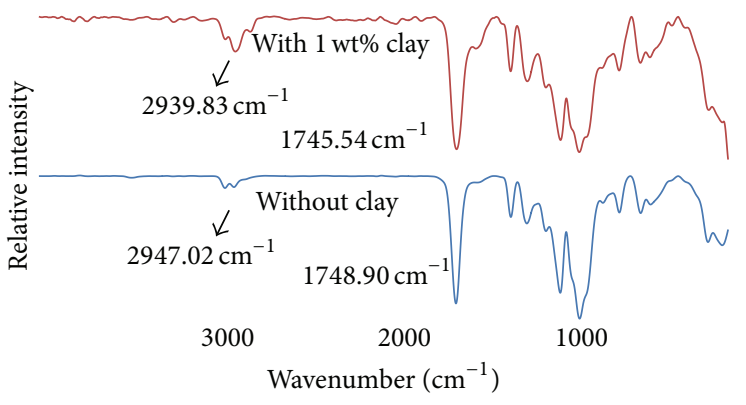

FIGURE 1: FTIR spectra of PLA/PCL/OPMF biocomposites and PLA/PCL/1 wt\% clay/OPMF hybrid composites.

samples were immersed at $25^{\circ} \mathrm{C}$ of distilled water for up to 30 days. Mass uptakes of the samples were measured periodically by removing them from the water bath. The samples were wiped with the tissue paper to remove the surface water. The moisture uptake expressed in percent weight gain, $\Delta M$, is

$$
\Delta M=\frac{M_{t}-M_{o}}{M_{o}} \times 100 \%,
$$

where $M_{t}=$ mass of sample after immersion and $M_{o}=$ mass of sample before immersion.

\section{Results and Discussion}

3.1. The Fourier Transform Infrared Spectroscopy (FTIR). FTIR spectra of PLA/PCL/OPMF biocomposites and PLA/ PCL/1 wt\% clay/OPMF hybrid composites are shown in Figure 1. Both composites exhibit strong absorbance peak at $1748.90 \mathrm{~cm}^{-1}$ and $1745 \mathrm{~cm}^{-1}$, respectively, indicating the presence of $\mathrm{C}=\mathrm{O}$ stretching. Besides, $\mathrm{C}-\mathrm{H}$ stretching is present in both composites but the intensity of the peak for PLA/PCL/1 wt\% clay/OPMF hybrid composites is higher than PLA/PCL/OPMF biocomposites with the peak at $2939 \mathrm{~cm}^{-1}$ and $2947 \mathrm{~cm}^{-1}$, respectively. Shifting of peaks in IR spectra is observed when there is strong interaction in polymer blends [12]. Therefore, peak shifting is observed when $1 \mathrm{wt} \%$ of clay was incorporated into biocomposites which indicated that there might be some physical interaction between PLA, PCL, clay, and OPMF in composites.

3.2. Tensile Properties. In our previous studies [2], we reported that the addition of $1 \mathrm{wt} \%$ of nanoclay successfully increases the tensile strength and elongation at break but decreases the tensile modulus of PLA/PCL/OPMF biocomposites which is summarized in Table 1. PLA/PCL/OPMF biocomposites show the highest tensile strength at $10 \mathrm{wt} \%$ of the fiber loading and decrease with the increasing of fiber loading which results from poor dispersion of fibers which leads to agglomeration of fillers. Besides, fiber acts as included filler in the resin matrix, which weakens the composite due to poor interfacial adhesion and obstructs the stress propagation, which leads to reduction of tensile strength as the filler loading increases. The presence of hydrophilic nanoclay increases the overall tensile strength 
TABLE 1: Tensile properties of PLA/PCL/OPMF biocomposites and PLA/PCL/1 wt\% clay/OPMF hybrid composites.

\begin{tabular}{lccc}
\hline Sample & Tensile strength (MPa) & $\begin{array}{c}\text { Elongation at } \\
\text { break (mm) }\end{array}$ & Tensile modulus (MPa) \\
\hline PLA85/PCL15 & $45.94 \pm 1.75$ & $1.68 \pm 0.30$ & $902.92 \pm 50.69$ \\
PLA85/PCL15/10 wt\% OPMF & $33.48 \pm 2.44$ & $0.56 \pm 0.04$ & $884.80 \pm 44.16$ \\
PLA85/PCL15/20 wt\% OPMF & $27.99 \pm 1.34$ & $0.40 \pm 0.02$ & $878.73 \pm 44.79$ \\
PLA85/PCL15/30 wt\% OPMF & $22.43 \pm 1.37$ & $0.35 \pm 0.02$ & $723.37 \pm 31.37$ \\
PLA85/PCL15/1 wt\% clay/10 wt\% OPMF & $36.32 \pm 1.22$ & $0.74 \pm 0.02$ & $685.80 \pm 71.32$ \\
PLA85/PCL15/1 wt\% clay/20 wt\% OPMF & $32.32 \pm 0.55$ & $0.64 \pm 0.10$ & $661.17 \pm 46.36$ \\
PLA85/PCL15/1 wt\% clay/30 wt\% OPMF & $29.46 \pm 1.58$ & $0.61 \pm 0.02$ & $577.18 \pm 27.04$ \\
\hline
\end{tabular}

of hybrid composites which suggests that the presence of hydrophilic nanoclay acts as physical compatibilizing agents between hydrophilic fiber and hydrophobic matrix and thus improves the fiber/matrix adhesion of hybrid composites. This might be due to the addition of nanoclay which successfully improves the miscibility of PLA/PLA in blends [1], while at the same time the presence of hydrophilic nanoclay is more compatible with hydrophilic fiber which enhances better physical interaction between fiber and matrix resulting in better mechanical properties of hybrid composites.

The addition of fiber decreases the elongation at break of composites from $1.68 \mathrm{~mm}$ to $0.56 \mathrm{~mm}$ (PLA/PCL/OPMF biocomposites) and $0.74 \mathrm{~mm}$ (PLA/PCL/OPMF/1 wt\% clay hybrid composites), respectively, at $10 \mathrm{wt} \%$ fiber loading. The addition of fiber into matrix causes composites to become stiffer and harder as the segment mobility of the composites is reduced which leads to low elongation. On the other hand, the addition of hydrophilic nanoclay improves the fiber/matrix adhesion of hybrid composites and also stress transfer within hybrid composites which enhance the flexibility of the composites. Therefore, PLA/PCL/OPMF/1 wt $\%$ clay hybrid composites show better elongation at break than PLA/PCL/OPMF biocomposites.

Tensile modulus of PLA/PCL/OPMF biocomposites and $\mathrm{PLA} / \mathrm{PCL} / \mathrm{OPMF} / 1 \mathrm{wt} \%$ clay hybrid composites indicates that the overall tensile modulus of biocomposites is higher than hybrid composites. Therefore, this implies that the addition of hydrophilic nanoclay decreases the stiffness of the composites as the flexibility of composites increase which leads to lower tensile modulus.

3.3. Flexural Properties. Flexural strength of PLA/PCL/ OPMF biocomposites and PLA/PCL/1wt\% clay/OPMF hybrid composites is illustrated in Figure 2. The addition of $1 \%$ clay in hybrid compositesshows better flexural strength $(36.53 \mathrm{MPa})$ compared to biocomposites $(21.45 \mathrm{MPa})$ at $10 \mathrm{wt} \%$ fiber loading. Therefore, the addition of clay has positive effect on flexural strength of hybrid composites due to better interfacial adhesion between matrix and filler which will improve stress transfer from matrix to filler resulting in higher values of flexural strength. Weak fiber/matrix interfacial bonding results in poor flexural properties [13]. When higher amount of fiber is incorporated into the composites, flexural strength decreases. This is due to the increment of population of fiber defects and fiber ends with

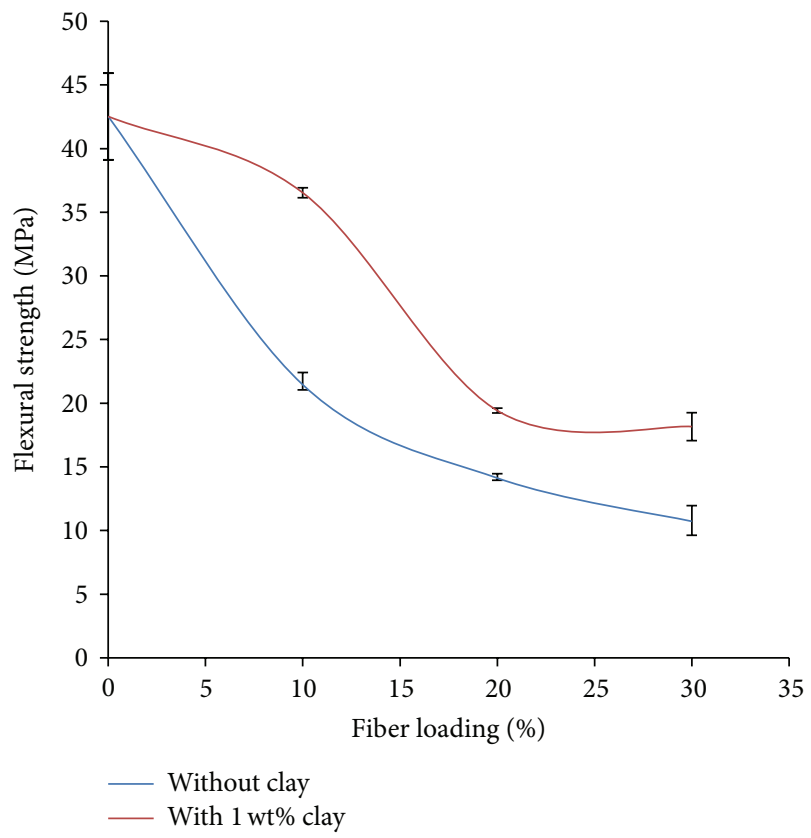

FIGURE 2: Flexural strength of PLA/PCL/OPMF biocomposites and PLA/PCL/1 wt\% clay/OPMF hybrid composites.

increased fiber content. The fiber defects could act as source of stress concentration in composites [14].

Figure 3 shows flexural modulus of PLA/PCL/OPMF biocomposites and PLA/PCL/1 wt\% clay/OPMF hybrid composites. The biocomposites show increment in flexural modulus from $2437.80 \mathrm{MPa}$ to $2797.00 \mathrm{MPa}$, while hybrid composites do not show changes in flexural modulus (2433.20 MPa) when $10 \mathrm{wt} \%$ of fiber was added. When the amount of fiber increases, the flexural modulus of hybrid composites increases and flexural modulus of biocomposites decreases. The increasing trend in flexural modulus with the increment amount of fiber for hybrid composites due to the addition of fillers with higher stiffness than matrix is mentioned by [15]. However, biocomposites show decrement of flexural modulus with increment of fiber loading due to poor interfacial adhesion between fiber and matrix which leads to low flexural modulus.

3.4. The Izod Impact Strength. Impact strength of PLA/PCL/ OPMF biocomposites and PLA/PCL/1 wt\% clay/OPMF 


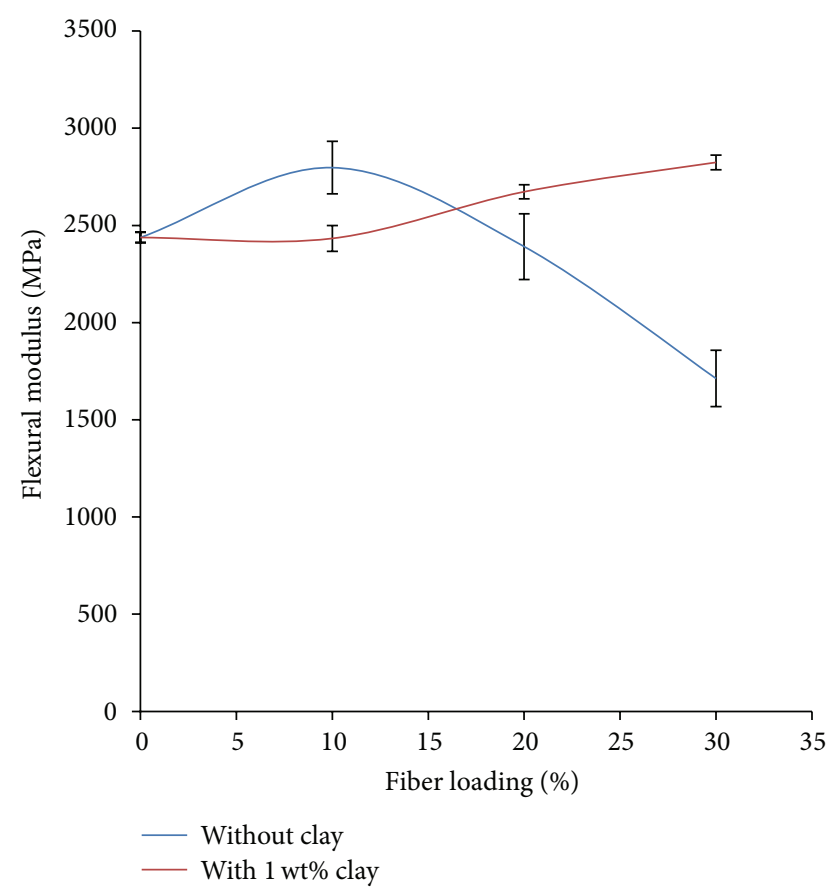

FIgURE 3: Flexural modulus of PLA/PCL/OPMF biocomposites and PLA/PCL/1 wt $\%$ clay/OPMF hybrid composites.

hybrid composites is illustrated in Figure 4. The impact strength decreases from $188.70 \mathrm{~J} / \mathrm{m}$ (PLA85/PCL15) to $82.37 \mathrm{~J} / \mathrm{m}$ and $95.44 \mathrm{~J} / \mathrm{m}$ for biocomposites and hybrid composites, respectively, at $10 \mathrm{wt} \%$ fiber loading. When fiber is incorporated into matrix, poor energy absorbing capability of fiber inhibit deformation and ductile mobility of polymer molecules which lower the ability of composites to absorb energy during crack propagation. Besides, less energy is required to initiate a crack as fiber creates high stress concentration regions [16]. However, the impact strength of hybrid composites is higher than biocomposites as the addition of clay improves impact strength of hybrid composites due to better fiber/matrix adhesion in hybrid composites compared to biocomposites.

3.5. Thermogravimetric Analysis (TGA). Previously we reported that incorporation of nanoclay improves the thermal stability of PLA/PCL/OPMF biocomposites [2]. The PLA/PCL/OPMF biocomposites show onset temperature of $196.01^{\circ} \mathrm{C}$, which increases to $221.12^{\circ} \mathrm{C}$ when clay is added to the biocomposites. Table 2 shows the thermal properties of PLA/PCL/OPMF biocomposites and PLA/PCL/1 wt\% clay/ OPMF hybrid composites. The increment of thermal stability of hybrid composites due to clay can hinder the permeability of volatile degradation products out of the materials. The dispersed clay forms a barrier which delays the release of thermal degradation products compared to the neat polymer [17].

3.6. Dynamic Mechanical Analysis (DMA). The storage modulus $\left(G^{\prime}\right)$ of PLA/PCL/OPMF biocomposites and

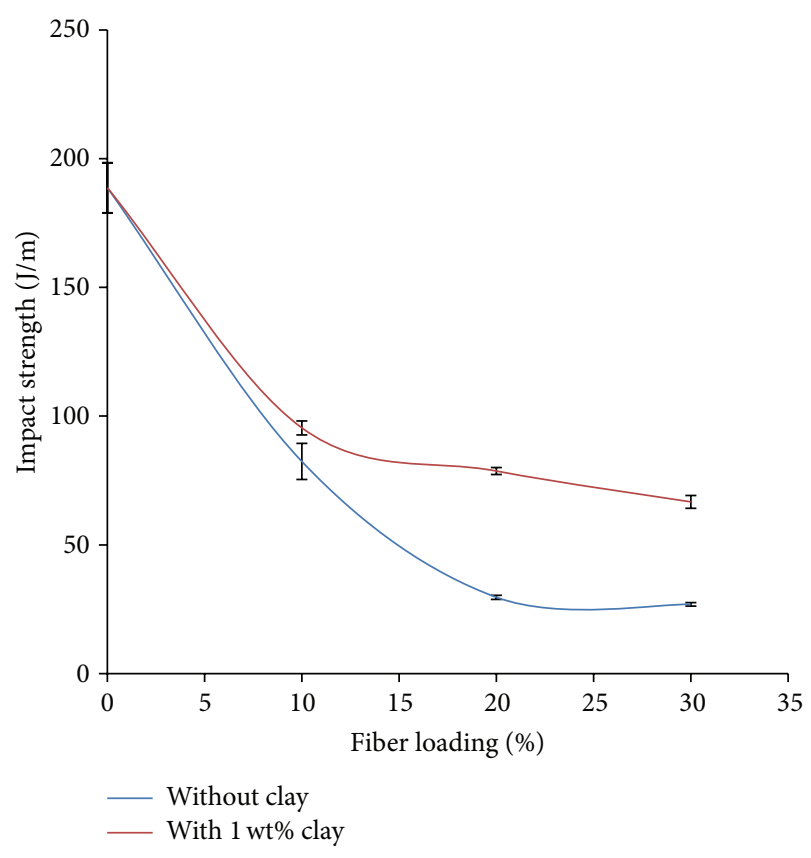

FIGURE 4: Impact strength of PLA/PCL/OPMF biocomposites and PLA/PCL/1 wt\% clay/OPMF hybrid composites.

PLA/PCL/1 wt\% clay/OPMF hybrid composites is illustrated in Figure 5. All the fiber loading in composites for DMA testing is $10 \mathrm{wt} \%$. Increment of $G^{\prime}$ after addition of fibers is due to incorporation of high modulus fibers in the matrix. The value of storage modulus decreases at higher temperature due to loss in stiffness of the fibers [18]. The $G^{\prime}$ results show agreement with the flexural modulus results as biocomposites show higher tensile modulus than hybrid composites. The addition of clay shows considerable effect on the elastic properties of hybrid composites by reducing the stiffness of the hybrid composites.

Figure 6 shows the loss modulus $\left(G^{\prime \prime}\right)$ of PLA/PCL/ OPMF biocomposites and PLA/PCL/1wt\% clay/OPMF hybrid composites. All the fiber loading in composites for DMA testing is $10 \mathrm{wt} \%$. Loss modulus indicates the material's ability to dissipate energy in the form of heat or molecular rearrangements during the deformation [19]. The loss modulus accounts for the viscous component of the complex modulus or the out of phase component with the applied strain which normally increases with the addition of filler [20]. The addition of fiber increases the $G^{\prime \prime}$ of biocomposites and hybrid composites at the temperature around $-68^{\circ} \mathrm{C}$ and then decreases at $48^{\circ} \mathrm{C}$. The addition of clay to biocomposites slightly shifts $T_{g}$ of biocomposites from $-67.7^{\circ} \mathrm{C}$ to $-67.0^{\circ} \mathrm{C}$ at PCL region and also from $47.6^{\circ} \mathrm{C}$ to $46.5^{\circ} \mathrm{C}$ at PLA region which suggests that the incorporation of clay slightly compatibilizes the biocomposites resulting in better mechanical properties of hybrid composites than biocomposites.

Figure 7 illustrated the loss factor $(\tan \delta)$ of PLA/PCL/ OPMF biocomposites and PLA/PCL/1 wt\% clay/OPMF hybrid composites. All the fiber loading in composites for 
TABLE 2: Thermal properties of PLA/PCL/OPMF biocomposites and PLA/PCL/1 wt\% clay/OPMF hybrid composites.

\begin{tabular}{lccc}
\hline Sample & Onset temperature $\left({ }^{\circ} \mathrm{C}\right)$ & Offset temperature $\left({ }^{\circ} \mathrm{C}\right)$ & $\%$ of degradation \\
\hline PLA/PCL/OPMF & 196.01 & 473.84 & 72.78 \\
PLA/PCL/1 wt\% clay/OPMF & 221.12 & 458.36 & 71.08 \\
\hline
\end{tabular}

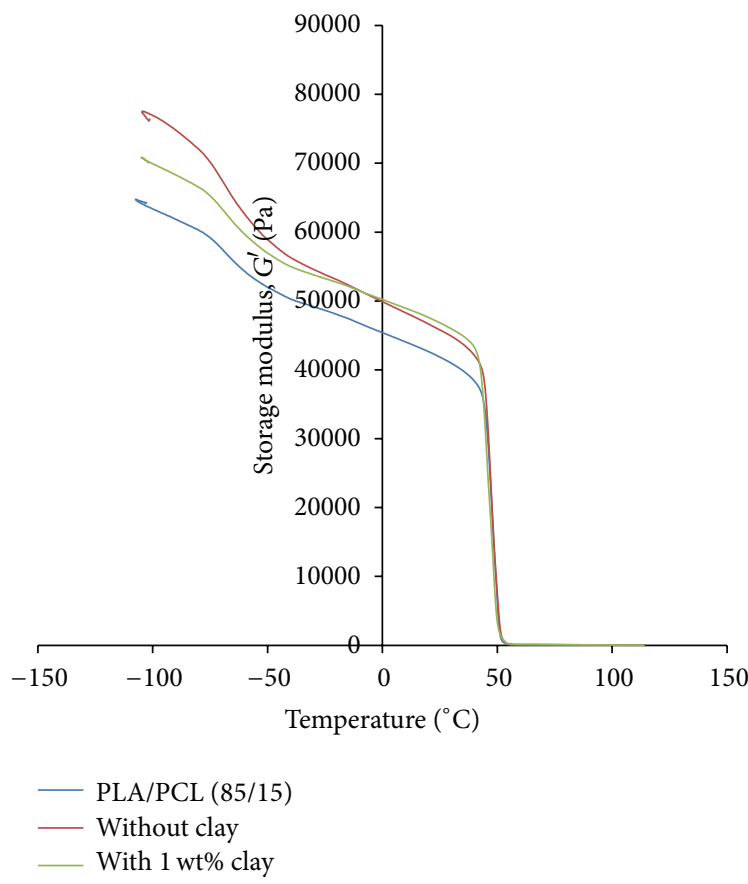

Figure 5: Storage modulus of PLA/PCL/OPMF biocomposites and PLA/PCL/1 wt\% clay/OPMF hybrid composites.

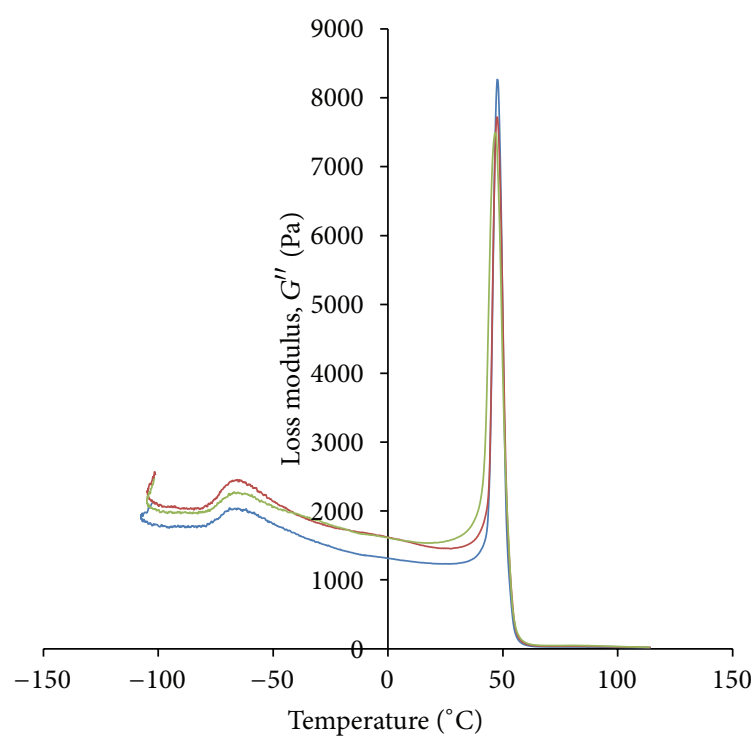

\footnotetext{
- PLA/PCL $(85 / 15)$

- Without clay

— With 1 wt $\%$ clay
}

FIGURE 6: Loss modulus of PLA/PCL/OPMF biocomposites and PLA/PCL/1 wt $\%$ clay/OPMF hybrid composites.

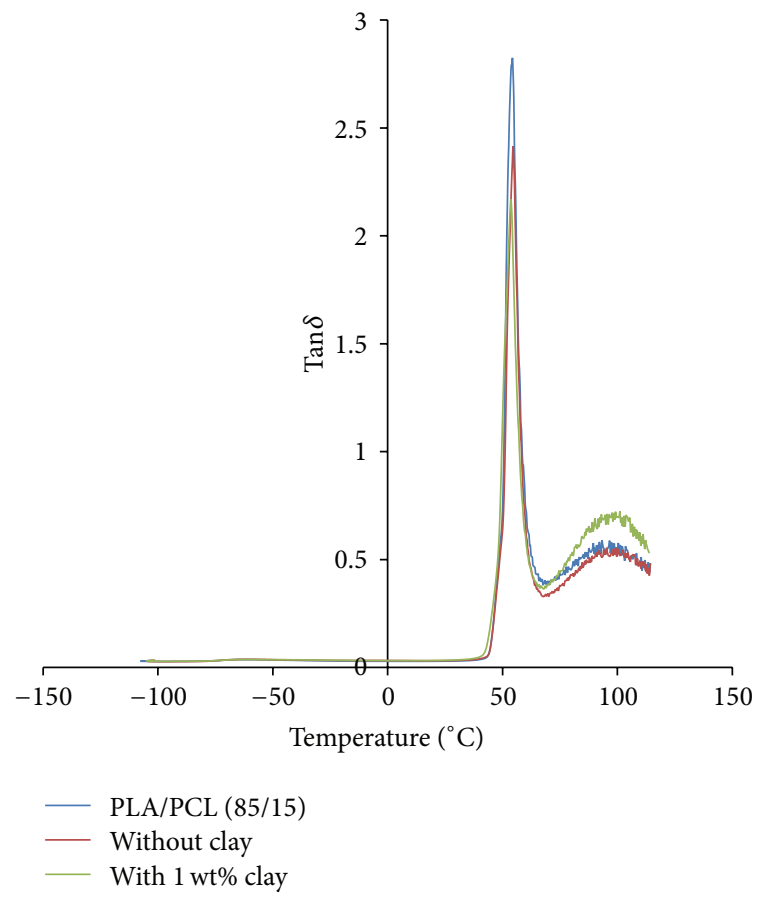

FIgURE 7: Tan $\delta$ of PLA/PCL/OPMF biocomposites and PLA/PCL/ $1 \mathrm{wt} \%$ clay/OPMF hybrid composites.

DMA testing is $10 \mathrm{wt} \%$. The addition of fiber decreases $\tan \delta$ in the glass transition region because molecular mobility of the composites decreased and the mechanical loss to overcome interfriction between molecular chains is reduced. Normally, damping of the polymer is much greater than fibers. Therefore, the addition of fibers to polymer matrix will increase the elasticity and decrease the viscosity and hence less energy will be used to overcome the frictional forces between molecular chains as to decrease mechanical loss [21]. The higher the damping at the interface, the poorer the interfacial adhesion between fiber and matrix [22]. Besides, composites with poor interfacial bonding tend to dissipate more energy compared with composites with good interfacial bonding. Therefore, addition of clay to biocomposites improves fiber/matrix adhesion as hybrid composites show lower $\tan \delta$ than biocomposites.

3.7. Scanning Electron Microscopy (SEM). In our previous paper [2], we reported that PLA/PCL/OPMF biocomposites consist of cavity as fiber has been pulled out from matrix which indicated poor fiber/matrix adhesion as fiber could not provide an efficient stress transfer from the matrix to the filler causing them to have lower mechanical properties in response to stress. On the other hand, 
PLA/PCL/OPMF/1 wt\% clay hybrid composites show better fiber/matrix adhesion as no cavity is present and fiber breakage could be seen on facture surfaces indicating better fiber/matrix adhesion. Therefore, the SEM results support the tensile properties results as the biocomposites show low strength due to poor stress transfer between matrix and fiber in composites which cause the composites to become brittle. On the other hand, SEM results also support the tensile properties results that hybrid composites show better mechanical properties than biocomposites.

3.8. Water Sorption Test. Water absorption of PLA/PCL/ OPMF biocomposites and PLA/PCL/1wt\% clay/OPMF hybrid composites is shown in Figure 8. The fiber absorbs water due to the presence of hydroxyl groups which absorb water through the formation of hydrogen bonding [23]. All composites show a sharp increment in water absorption at the beginning and then remain constant around 10 days with the maximum water absorption being $5.81 \%$ and $5.29 \%$ for biocomposites and hybrid composites, respectively. Water absorption of all composites is typical type of the Fickian diffusion behaviour. In Fick's law, the concentration gradient is the driving force for diffusion and amount of the component diffused in a function of time. Generally, moisture absorption process follows the prediction of Fick's law as the mass of water absorbed increases linearly with square root of time until reach equilibrium plateau [24]. Biocomposites show higher water absorption than hybrid composites which might be due to the weak fiber/matrix adhesion leads to more void in composites which can act as pathways for water diffusion into the composites. Therefore, addition of clay improves fiber/matrix adhesion while enhancing water resistance of composites at the same time.

\section{Conclusion}

In these studies, the addition of $1 \mathrm{wt} \%$ hydrophilic nanoclay successfully improves the overall flexural strength and impact strength of PLA/PCL/OPMF biocomposites. DMA analysis shows decrement in storage modulus when nanoclay was added indicating that addition of nanoclay has considerable effect on the elastic properties of hybrid composites by reducing the stiffness of the hybrid composites. Loss modulus shows that the addition of nanoclay to biocomposites slightly shifts $T_{g}$ of biocomposites from $-67.7^{\circ} \mathrm{C}$ to $-67.0^{\circ} \mathrm{C}$ at PCL region and also from $47.6^{\circ} \mathrm{C}$ to $46.5^{\circ} \mathrm{C}$ at PLA region which suggests that the incorporation of nanoclay slightly compatibilizes the biocomposites resulting in better mechanical properties of PLA/PCL/1 wt $\%$ clay/OPMF hybrid composites than biocomposites. Tan $\delta$ indicated that hybrid composites dissipate less energy compared to biocomposites indicating that addition of clay to biocomposites improves fiber/matrix adhesion. Water sorption test shows that the addition of nanoclay improves fiber/matrix adhesion while enhancing water resistance of composites at the same time. Therefore, the addition of nanoclay in hybrid composites makes hybrid composites possess good strength and properties which is comparable with some conventional plastics. Besides,

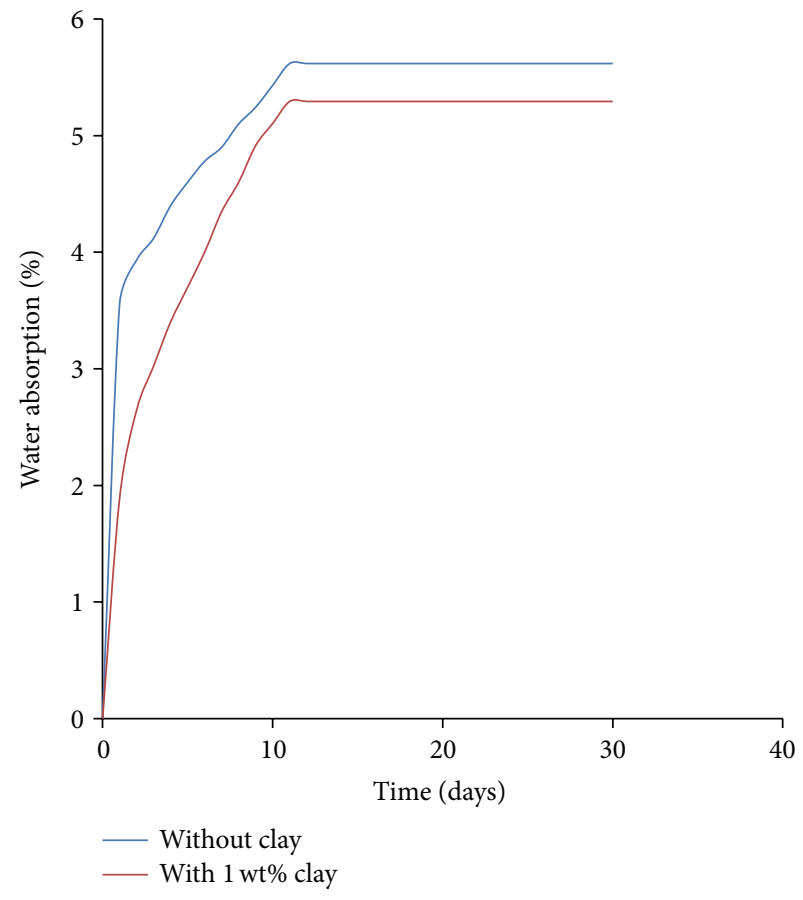

FIGURE 8: Water absorption of PLA/PCL/OPMF biocomposites and PLA/PCL/1 wt\% clay/OPMF hybrid composites.

the incorporation of natural fibers in hybrid composites lowering the cost of biodegradable polymer which wider the application of biodegradable polymer based composites. The applications of the hybrid composites might be more suitable for single-use materials that do not require very high strength, while at the same time biodegradability and environment friendly are one of the concerns of selection of materials.

\section{Conflict of Interests}

The authors declare that there is no conflict of interests with any financial organization regarding the materials discussed in the paper.

\section{Acknowledgments}

The authors would like to thank the Research University Grant Scheme (RUGS), UPM, for its financial support. All the technical staff in the Department of Chemistry, Faculty of Science, Universiti Putra Malaysia, are greatly acknowledged for their assistance.

\section{References}

[1] C. C. Eng, N. A. Ibrahim, N. Zainuddin et al., "Enhancement of mechanical and thermal properties of polylactic acid/polycaprolactone blends by hydrophilic nanoclay," Indian Journal of Materials Science, vol. 2013, Article ID 816503, 11 pages, 2013. 
[2] C. C. Eng, N. A. Ibrahim, N. Zainuddin, H. Ariffin, W. M. Z. Wan Yunus, and Y. Y. Then, "Effect of hydrophilic nanoclay on morphology, thermal and mechanical properties of polylactic acid/polycaprolactone/oil palm mesocarp fiber biocomposites," International Journal of the Institute of Materials Malaysia, vol. 1, no. 1, pp. 51-70, 2014.

[3] P. Wambua, J. Ivens, and I. Verpoest, "Natural fibres: can they replace glass in fibre reinforced plastics?" Composites Science and Technology, vol. 63, no. 9, pp. 1259-1264, 2003.

[4] J. E. Riccieri, L. H. de Carvalho, and A. Vázquez, "Interfacial properties and initial step of the water sorption in unidirectional unsaturated polyester/vegetable fiber composites," Polymer Composites, vol. 20, no. 1, pp. 29-37, 1999.

[5] M. A. A. Mohammed, A. Salmiaton, W. A. K. G. Wan Azlina, M. S. Mohammad Amran, A. Fakhru'L-Razi, and Y. H. Taufiq-Yap, "Hydrogen rich gas from oil palm biomass as a potential source of renewable energy in Malaysia," Renewable and Sustainable Energy Reviews, vol. 15, no. 2, pp. 1258-1270, 2011.

[6] W. P. Q. Ng, H. L. Lam, F. Y. Ng, M. Kamal, and J. H. E. Lim, "Waste-to-wealth: green potential from palm biomass in Malaysia," Journal of Cleaner Production, vol. 34, pp. 57-65, 2012.

[7] H. Balakrishnan, A. Hassan, M. U. Wahit, A. A. Yussuf, and S. B. A. Razak, "Novel toughened polylactic acid nanocomposite: mechanical, thermal and morphological properties," Materials and Design, vol. 31, no. 7, pp. 3289-3298, 2010.

[8] J. T. Yeh, C. J. Wu, C. H. Tsou et al., "Study on the crystallization, miscibility, morphology, properties of poly(lactic acid)/poly $(\varepsilon-$ caprolactone) blends," Polymer-Plastics Technology and Engineering, vol. 48, no. 6, pp. 571-578, 2009.

[9] K. Majeed, M. Jawaid, A. Hassan et al., "Potential materials for food packaging from nanoclay/natural fibres filled hybrid composites," Materials \& Design, vol. 46, pp. 391-410, 2013.

[10] M. J. John and S. Thomas, "Biofibres and biocomposites," Carbohydrate Polymers, vol. 71, no. 3, pp. 343-364, 2008.

[11] B. Kord, "Effect of nanoparticles loading on properties of polymeric composite based on hemp fiber/polypropylene," Journal of Thermoplastic Composite Materials, vol. 25, no. 7, pp. 793-806, 2012.

[12] B. K. Kim and C. H. Choi, "Melt blends of poly(methyl methacrylate) with a phenoxy," Polymer, vol. 37 , no. 5, pp. 807-812, 1996.

[13] H. P. S. Abdul Khalil, A. M. Issam, M. T. Ahmad Shakri, R. Suriani, and A. Y. Awang, "Conventional agro-composites from chemically modified fibres," Industrial Crops and Products, vol. 26, no. 3, pp. 315-323, 2007.

[14] M. A. Sawpan, K. L. Pickering, and A. Fernyhough, "Flexural properties of hemp fibre reinforced polylactide and unsaturated polyester composites," Composites A: Applied Science and Manufacturing, vol. 43, no. 3, pp. 519-526, 2012.

[15] C. R. Reddy, A. P. Sardashti, and L. C. Simon, "Preparation and characterization of polypropylene-wheat straw-clay composites," Composites Science and Technology, vol. 70, no. 12, pp. 1674-1680, 2010.

[16] B. D. Park and J. J. Balatinecz, "Mechanical properties of woodfiber/toughened isotactic polypropylene composites," Polymer Composites, vol. 18, no. 1, pp. 79-89, 1997.

[17] T. Agag, T. Koga, and T. Takeichi, "Studies on thermal and mechanical properties of polyimide-clay nanocomposites," Polymer, vol. 42, no. 8, pp. 3399-3408, 2001.
[18] D. Shanmugam and M. Thiruchitrambalam, "Static and dynamic mechanical properties of alkali treated unidirectional continuous Palmyra Palm Leaf Stalk Fiber/jute fiber reinforced hybrid polyester composites," Materials \& Design, vol. 50, pp. 533-542, 2013.

[19] F. Rezaei, R. Yunus, and N. A. Ibrahim, "Effect of fiber length on thermomechanical properties of short carbon fiber reinforced polypropylene composites," Materials and Design, vol. 30, no. 2, pp. 260-263, 2009.

[20] S. Singh, A. K. Mohanty, and M. Misra, "Hybrid bio-composite from talc, wood fiber and bioplastic: fabrication and characterization," Composites A: Applied Science and Manufacturing, vol. 41, no. 2, pp. 304-312, 2010.

[21] W. Liu, M. Misra, P. Askeland, L. T. Drzal, and A. K. Mohanty, “'Green' composites from soy based plastic and pineapple leaf fiber: Fabrication and properties evaluation," Polymer, vol. 46, no. 8, pp. 2710-2721, 2005.

[22] S. Dong and R. Gauvin, "Application of dynamic mechanical analysis for the study of the interfacial region in carbon fiber/epoxy composite materials," Polymer Composites, vol. 14, no. 5, pp. 414-420, 1993.

[23] H. P. S. Abdul Khalil, H. Ismail, M. N. Ahmad, A. Ariffin, and K. Hassan, "The effect of various anhydride modifications on mechanical properties and water absorption of oil palm empty fruit bunches reinforced polyester composites," Polymer International, vol. 50, no. 4, pp. 395-402, 2001.

[24] V. Vilay, M. Mariatti, R. Mat Taib, and M. Todo, "Effect of fiber surface treatment and fiber loading on the properties of bagasse fiber-reinforced unsaturated polyester composites," Composites Science and Technology, vol. 68, no. 3-4, pp. 631-638, 2008. 

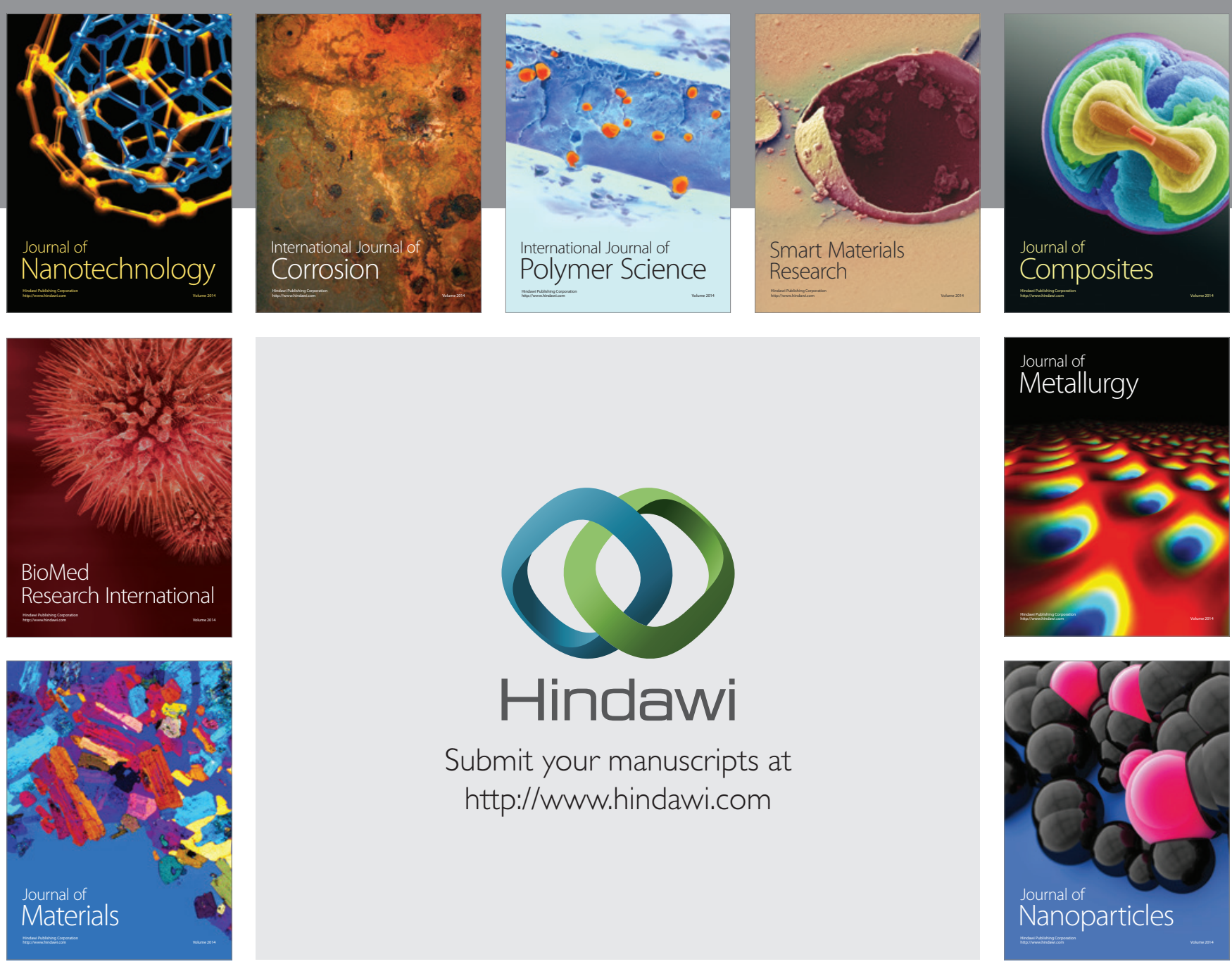

Submit your manuscripts at http://www.hindawi.com
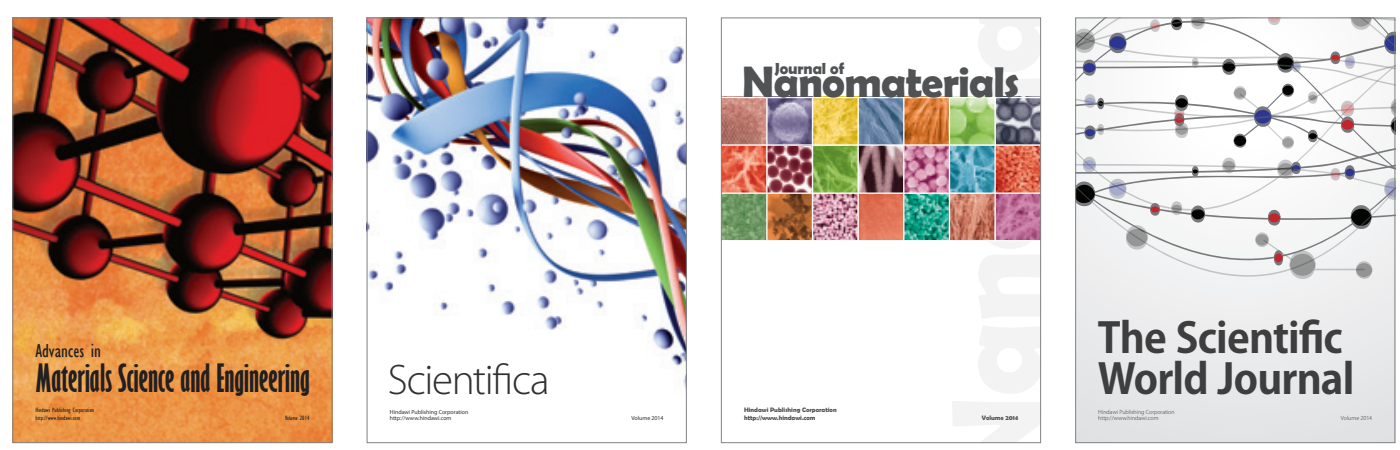

\section{The Scientific World Journal}
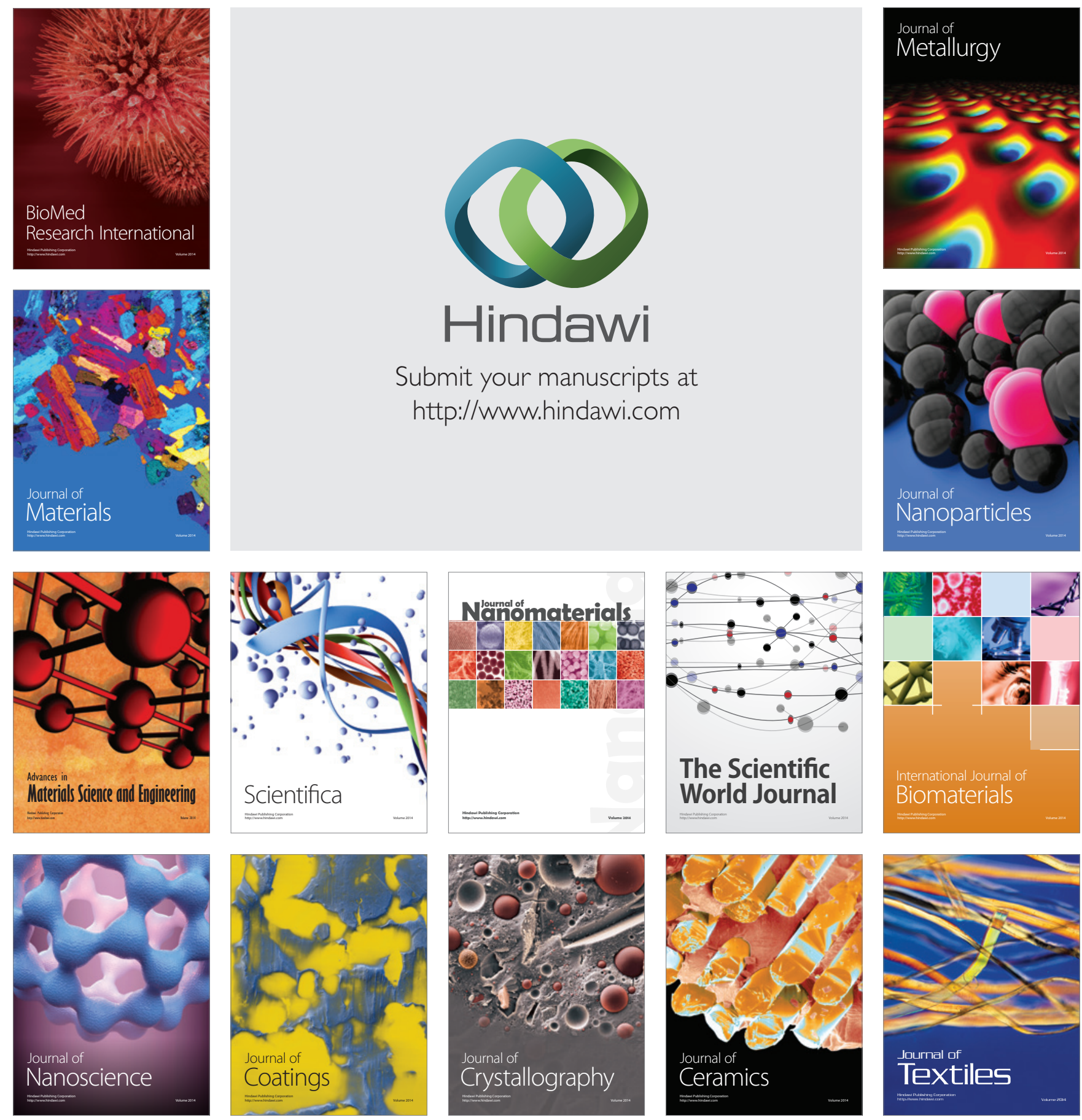